\title{
Clinical spectrum of congenital heart diseases in a tertiary care hospital
}

\author{
Phuljhele S. ${ }^{1}$, Dewangan S. ${ }^{2}$, Thombre $\mathbf{P}^{3}$ \\ ${ }^{1}$ Dr. Sharja Phuljhele, Professor, ${ }^{2}$ Dr. Shashikant Dewangan, Assistant Professor, ${ }^{3}$ Dr. Pranali Thombre, Resident; all \\ authors are affiliated with Department of Paediatrics, Pt J.N.M. Medical College, Raipur, CG, India.
}

Address for Correspondence: Dr. Shashikant Dewangan, Email: drshashikantdewangan@gmail.com

\begin{abstract}
Introduction- In developing countries congenital heart diseases (CHDs) causes deaths of thousands of children. A study is necessary to understand incidence and clinical spectrum of CHDs so that early diagnosis and intervention can be done. Material and Methods - Newborns and children up to the age of 14 years attending pediatric OPD as well as admitted in ward with CHDs enrolled for study. Data were analyzed using SPSS system version 21. Results- A total of 400 children with CHDs included for final analysis. Male to Female ratio is 1.78:1. Most common CHDs was Ventricular septal defect followed by Tetralogy of fallot. Major symptoms were cough, difficulty in breathing, poor weight gain and suck rest suck cycle. Maternal risk factors found were consanguinity, maternal diabetes mellitus, maternal hypertension, maternal seizure disorder, maternal obesity, systematic lupus erythematosus etc. Conclusion- VSD is most common acyanotic CHD. Males are more affected with CHDs. Consanguinity and Maternal Diabetes are important risk factors for CHDs.
\end{abstract}

Key words: Congenital heart diseases, Echocardiography, clinical features, Maternal risk factors

\section{Introduction}

Congenital Heart Diseases (CHDs) is commonest of all congenital lesions and most common type of heart disease in children [1]. Congenital Heart Diseases (CHDs), in a definition proposed by Mitchell et al is, a gross structural abnormality of the heart or intrathorasic great vessels that is actually or potentially of functional significance [2]. The reported incidence of CHDs is 8$10 \backslash 1000$ according to various studies from different parts of world, with higher rates in stillbirth, spontaneous abortions and prematurity [3]. Various studies reported incidence of CHDs in India from 0.8 to 4.2 per 1000 live births [4-9]. Approximately $10 \%$ of infant mortality in our country is due to CHDs. In developing countries CHDs causes deaths of thousands of children [10]. Due to improved and more available diagnostic facilities many CHDs are diagnosed in initial years of life. In spite of early diagnosis overall prognosis is still poor because of lack of centres expert in correction of CHDs.

Manuscript received $11^{\text {th }}$ September 2016

Reviewed: $24^{\text {th }}$ September 2016

Author Corrected: $5^{\text {th }}$ October 2016

Accepted for Publication $18^{\text {th }}$ October 2016
Early, accurate diagnosis and timely intervention is the key for better prognosis in CHD. Emergence of crosssectional echocardiography and then colour flow mapping in 1980s has provided a unique tool to study noninvasively the change in form and function of congenitally malformed hearts also the response and sequelae of interventions. Elder and Hertz of Lund university in Sweden received the Lasker award in 1977 for their pioneering work in echocardiography during 1950s [11].

Echocardiography is a cheap and non-invasive modality with the advantage of reproducibility of results, instantaneous images and reliable level of accuracy. Now a day's 2D echocardiography with colour doppler provides comprehensive means for evaluating virtually all forms of CHDs both in adults and children [12]. In India pediatric echocardiography is not widely available even further optimal use of this technology is hampered by factors such as cost, lack of skilled persons and the absence of appropriate probes. The few studies carried out in India were either community or school based 
study they did not indicate clinical profile of CHD. A good reflection of incidence and pattern of CHD can be obtained by study of congenital heart disease in general hospital which serves majority of population around. Hence we decided to describe the spectrum of CHDs seen in a tertiary care hospital.

\section{Material and Methods}

This prospective observational study was carried over 4 year from June 2011 to June 2015 on children from newborn to 14 years of age admitted in paediatric ward and attending OPD with cardiovascular and respiratory problems in Dr.BRAM hospital Raipur. After enrolment detailed history of patients was taken to know there clinical presentation and complete clinical examination was also done. Diagnosis of CHDs were established by detailed 2-D Echocardiography and colour doppler. Relevant investigations like Xray, ECG, complete blood count, serum investigations were also carried out. All the data related to history, examination and investigations was filled in pro forma. Datasheet was prepared and analysed by using SPSS system version 21.

Two dimensional and colour doppler echocardiography were done with Neonatal $(12 \mathrm{MHz})$ and Pediatric $(8 \mathrm{MHz})$ sector transducer. Echocardiographic examinations were completed according to recommendation of American society of Echocardiography (ASE) [13]. Complete doppler examination was according to the recommendations of ASE.

Children with cardiovascular and respiratory problem in whom diagnosis was confirmed by echocardiography were included in study. Operated cases of CHDs and those with acquired heart diseases were excluded from study.

\section{Result}

A total of 486 children from newborn to 14 years of age with heart diseases were examined over a period of 4 years. Out of which 35 cases were already operated and 51 were acquired heart diseases hence excluded from study. Total 400 children with CHDs were included in study for final analysis.

Table 1: Age and sex distribution of children with congenital heart diseases

\begin{tabular}{|c|c|c|c|}
\hline Types of CHD & Females & Males & Total (\%) \\
\hline Newborns & 16 & 32 & $48(12 \%)$ \\
\hline$<6$ months & 56 & 72 & $128(32 \%)$ \\
\hline $6-12$ months & 16 & 40 & $56(14 \%)$ \\
\hline $1-2$ yrs & 16 & 32 & $48(12 \%)$ \\
\hline$>2$ yrs & 40 & 80 & $120(30 \%)$ \\
\hline Total $(\%)$ & $\mathbf{1 4 4}(\mathbf{3 6 \%})$ & $\mathbf{2 5 6}(\mathbf{6 4 \% )}$ & $\mathbf{4 0 0 ( 1 0 0 \% )}$ \\
\hline
\end{tabular}

In our study higher prevalence of CHDs in males (64\%) as compared to female (36\%)

Table 2: Distribution of various congenital heart diseases

\begin{tabular}{|c|c|c|c|}
\hline Types of CHD & Males & Females & Total (\%) \\
\hline VSD & 70 & 46 & $116(29 \%)$ \\
\hline PDA & 46 & 29 & $75((18.7 \%)$ \\
\hline ASD & 24 & 22 & $46(11.5 \%)$ \\
\hline COA & 10 & 9 & $19(4.7 \%)$ \\
\hline TOF & 58 & 22 & $70(20 \%)$ \\
\hline d-TGA & 5 & 1 & $6(1.5 \%)$ \\
\hline Tricuspid atresia & 5 & 2 & $6(1.5 \%)$ \\
\hline TAPVC & 4 & 11 & $45(11.25 \%)$ \\
\hline Others & 34 & $\mathbf{1 4 4}(\mathbf{3 6 \%})$ & $\mathbf{4 0 0 ( 1 0 0 \% )}$ \\
\hline Total & $\mathbf{2 5 6}(\mathbf{6 4 \% )}$ & & \\
\hline
\end{tabular}


In this study most common CHD is Ventricular septal defect (29\%) followed by TOF (20\%). This study found TOF as most common cyanotic CHDs amounting to $64.5 \%$ of total cyanotic CHDs.

Table-3: Distribution of different presenting symptoms

\begin{tabular}{|c|c|c|}
\hline Symptoms & No of patients & 60.0 \\
\hline Cough & 30 & 62.0 \\
\hline Difficulty in breathing & 31 & 44.0 \\
\hline Fever & 22 & 46.0 \\
\hline SRS cycle & 23 & 62.0 \\
\hline Chest inf & 31 & 36.0 \\
\hline Cyanosis & 18 & 12.0 \\
\hline Squating & 6 & 2.0 \\
\hline Chest pain & 1 & 72.0 \\
\hline Poor wt & 36 & 60.0 \\
\hline Fatigability & 30 & $\mathbf{1 0 0 . 0}$ \\
\hline Total & $\mathbf{5 0}$ & \\
\hline
\end{tabular}

Major symptoms are cough (60\%), difficulty in breathing (60\%), Poor wt gain (72\%) and Suck rest suck cycle (46\%) and Bluish discolouration of body $(36 \%)$.

Table-4: Association with different maternal risk factors

\begin{tabular}{|c|c|c|}
\hline Risk factors & No. Of Patients & Percent \\
\hline Maternal DM & 5 & $1.25 \%$ \\
\hline Maternal Hypertension & 4 & $2.5 \%$ \\
\hline Consaguinity & 10 & $0.5 \%$ \\
\hline Primary infertility & 2 & 0 \\
\hline Radiation exposure & 0 & $0.75 \%$ \\
\hline Fever with rash & 3 & $1 \%$ \\
\hline Seizure disorder & 4 & $0.25 \%$ \\
\hline Maternal obesity & 1 & $0.5 \%$ \\
\hline SLE & 2 & $92.25 \%$ \\
\hline NO risk factor & 369 & $1 \%$ \\
\hline
\end{tabular}

In $92.25 \%$ cases no maternal risk factor found. In 10 (2.5\%) cases consanguinity was found. Other maternal risk factors were maternal diabetes mellitus $(1.25 \%)$, maternal hypertension $(1 \%)$, seizure disorder $(1 \%)$ etc.

\section{Discussion}

In our study $70 \%$ children were diagnosed by the age of 2 years. In an other Indian study $82.6 \%$ children were diagnosed between the ages of 0-3 years [4]. Delayed diagnosis of CHDs probably related to lack of diagnostic facilities, parental unawareness, social taboos and financial constraints. Similar findings were described in other studies [14]. Delay in recognition of CHDs has serious problems in long term outcome [15].
There may be increased morbidity and mortility associated with delayed diagnosis [16].

In our study male to female ratio is $1.78: 1$. This finding is similar to observation of other studies [6, 17,18 ]. Slightly higher prevalence of males in our study may be related to gender bias towards males. In our study most common CHD is VSD (29\%). VSD is most common 
CHD across the globe with average incidence of around $34 \%$ [19]. Other studies found incidence of VSD ranging from $34.6 \%-45 \%$ [4-9, 17, 18]. In many studies that included adult population found ASD as most common CHD [20-21]. This variation is due to the fact that small VSDs close during childhood and those with large VSDs die before adulthood.

We found higher incidence of TOF (20\%) against the global average of around 5\% [19]. Our study shows incidence of PDA and ASD $18.7 \%$ and $11.5 \%$ respectively. This is in contrast to average incidence of $10 \%$ and $13 \%$ of PDA and ASD respectively [19]. In a study from Kanpur reported incidence of PDA and ASD were $14.6 \%$ and $18.9 \%$ respectively [4]. Males have outnumbered female in TOF (2.63:1), VSD (1.52:1) and PDA (1.58:1) while there is approximately equal distribution of ASD and COA cases among males and females. In a study from bohemia there were significantly more girls than boys with PDA $(1: 1.66)$ and TOF $(1: 1.12)$ while a higher proportion of males were found with COA [22]. In an Indian study that included 10641 children up to 15 years of age boys to girls ratio in ASD was (4.3:1), in VSD was (1.6:1) and in PDA was (1.5:1) [4]. No girl child with TOF was found.

Cough, difficulty in breathing, poor weight gain and recurrent chest infection were major presenting symptoms in our study.

Poor weight gain and malnutrition is common in children with congenital heart disease [23]. Other clinical observations are similar to findings in other studies [24-25].

We found important clinical correlation of CHDs with consanguinity, maternal diabetes mellitus, maternal hypertension and seizure disorder. In a study from Saudi Arabia first cousin consanguinity was significantly associated with VSD, ASD, Pulmonary stenosis and Pulmonary atresia while there is no association found in TOF, PDA, COA, Tricuspid atresia and Aortic stenosis [26]. In a study from South India findings revealed that first cousin marriages and uncleniece marriages are equally significant in increasing CHDs [27]. Other studies also found consanguinity as important risk factor for CHDs [28, 29, 30]. Materanal diabetes and maternal use of antiepileptics are well known noninherited risk factor for congenital heart disease [31]. Preconceptional maternal diabetes was strongly associated with cardiovascular malformation of early embryonic origin [32].

Epidemiological studies of congenital heart diseases (CHDs) are essential for early detection, evaluation, proper management and to understand natural course of disease. This study demonstrates epidemiology of congenital heart diseases presenting to a tertiary care hospital. Thus it is hoped that this study more or less represents the spectrum of CHD in general population of Chhattisgarh region where Bhim Rao Ambedkar Memorial hospital is major general hospital serving population surrounding it.

\section{Conclusion}

In this part of world acyanotic CHDs are more common. VSD is most common acyanotic CHD while TOF is most common cyanotic CHD. Higher number of males are affected with CHDs. Around $44 \%$ of children are symptomatic by the age of 6 months. VSD, PDA and TOF are much more common in Males while ASD and COA have almost equal distribution among males and females. Majority of them were present to clinician with poor weight gain, difficulty in breathing, chest infection and fatigability. Consanguinity and maternal diabetes mellitus are important risk factor for CHDs.

Funding: Nil, Conflict of interest: None initiated, Permission from IRB: Yes

\section{References}

1. Schoen FJ. The Heart. In: Cortan RS, Kumar V, Robins SL, 6th ed. Robins Pathologic Basis of Disease. Philadelphia: W.B. Saunders Company, 1999; 543-600.

2. Hoffman JI, Kaplan S, Liberthson RR. Prevalence of congenital heart disease. Am Heart J. 2004 Mar; 147 (3):425-39.

3. Alabdulgader AA. Congenital heart disease in 740 subjects: epidemiological aspects. Ann Trop Paediatr. 2001 Jun;21(2):111-8.

4. Kapoor R, Gupta S. Prevalence of congenital heart disease, Kanpur, India. Indian Pediatr. 2008 Apr;45(4):309-11.

5. Mohd Ashraf, J Chowdhary, K Khajuria and AM Reyaz. Spectrum of Congenital Heart Diseases in Kashmir, India. Indian Pediatr. 2009 Dec;46 (12): 1107-8. 
6. Vaidyanathan $B^{1}$, Sathish G, Mohanan ST, Sundaram KR, Warrier KK, Kumar RK. Clinical screening for congenital heart disease at birth: a prospective study in a community hospital in Kerala. Indian Pediatr. 2011 Jan;48(1):25-30

7. Khali A, Aggarwal R, Thirupuram S, Arora R. Incidence of congenital heart disease among hospital live births in India. Indian Pediatr. 1994 May; 31 (5):519-27

8. Thakur JS, Negi PC, Ahluwalia SK, Sharma R, Bhardwaj R. Congenital heart disease among school children in shimla hills. Indian Heart J. 1995 May-Jun; 47(3):232-5.

9. Chadha SL, Singh N, Shukla DK. Epidemiological study of congenital heart disease. Indian J Pediatr. 2001 Jun;68(6):507-10.

10. Cohen AJ, Tamir A, Houri S, Abegaz B, Gilad E, Omohkdion S, Zabeeda D, Khazin V, Ciubotaru A, Schachner A. Save a child's heart: we can and we should. Ann Thorac Surg. 2001 Feb;71(2):462-8

11. Allen HD, Lange LW, Sahn DJ, Goldberg SJ, ultrasound cardiac diagnosis. Pediatr Clin North Am. 1978 Nov;25(4):677-706

12. Chung KJ, Simpson IA, Newman R, David JS, Frederick SS, Hesselink JR. Cine magnetic resonance imaging for evaluation of congenital heart disease: Role in pediatric cardiology compared with echocardiography and angiography. J Pediatr. 1988 Dec;113 (6): 1028-35.

13. Campbell RM, Douglas PS, Eidem BW, Lai WW, Lopez L, Sachdeva R. ACC/AAP/AHA/ASE/ HRS/SCAI/SCCT/SCMR/SOPE 2014 appropriate use criteria for initial transthoracic echocardiography in outpatient pediatric cardiology. J Am Coll Cardiol. 2014 Nov 11;64(19):2039-60

14. Rashid U, Qureshi AU, Hyder SN, Sadiq M. Pattern of congenital heart disease in a developing country tertiary care center: Factors associated with delayed diagnosis. Ann Pediatr Card 2016;9:210-5

15. Pfammatter JP ${ }^{1}$, Stocker FP. Delayed recognition of haemodynamically relevant congenital heart disease. Eur J Pediatr. 2001 Apr;160(4):231-4.
16. Massin MM, Dessy H. Delayed recognition of congenital heart disease. Postgraduate Medical Journal. 2006;82(969):468-70.

17. Shah GS, Singh MK, Pandey TR, Kalakheti BK, Bhandari GP . Incidence of congenital heart disease in tertiary care hospital. Kathmandu Univ Med J (KUMJ). 2008 Jan-Mar;6(1):33-6.

18. L. Kasturi, A.V. Kulkarni, A. Amin and V.A. Mashankar. Congenital heart disease: Clinical spectrum. Indian Pediatr. 1999 Sep; 36(9):953.

19. van der Linde D, Konings EE, Slager MA, Witsenburg M, Helbing WA, Takkenberg JJ, RoosHesselink JW. Birth prevalence of congenital heart disease worldwide: a systematic review and metaanalysis. J Am Coll Cardiol. 2011 Nov 15;58(21):22417. doi: 10.1016/j.jacc.2011.08.025.

20. Rahman F, Salman M, Akhter N, Patwary SR, Anam K, Rahman MM, Hasan Z, Uddin MJ, Khalil MM, Hafiiz MG, Zaman SM, Fatema N, Rashid MA, Banerjee SK, Haque SS, Chowdhury NA. Pattern of congenital heart diseases. Mymensingh Med J. 2012 Apr; 21(2):246-50

21. Shrestha B. Nepal's noble echocardiographydatabase with video clips and color still images: a single individual's 6 years' experience at the Echocardiography Lab of Nepal Medical College, Teaching Hospital. Nepal Med Coll J. 2012 Sep;14(3):180-6.

22. Samánek M. Boy:girl ratio in children born with different forms of cardiac malformation: a populationbased study. Pediatr Cardiol. 1994 Mar-Apr;15(2): 53-7.

23. Cameron JW, Rosenthal A, Olsan AD. Malnutrition in hospitalized children with congenital heart disease. Arch Pediatr Adolesc Med. 1995 Oct; 149(10): 1098-102.

24. Silove ED. Assessment and management of congenital heart disease in the newborn by district pediatrician. Arch Dis Child Fetal Neonatal Ed. 1994 Jan; 70(1):F71-4.

25. el Hag AI. Pattern of Congenital Heart Disease in Sudanese Children. East Afr Med J. 1994 Sep;71(9): 580-6. 
26. Becker SM, Al Halees Z, Molina C, Paterson RM. Consanguinity and congenital heart disease in Saudi Arabia. Am J Med Genet. 2001 Feb 15;99(1):8-13.

27. Ramegowda S, Ramachandra NB. Parental consanguinity increases congenital heart diseases in South India. Ann Hum Biol. 2006;33:519-28

28. El Mouzan MI, Al Salloum AA, Al Herbish AS, Qurachi MM, Al Omar AA. Consanguinity and major genetic disorders in Saudi children: a community-based cross-sectional study. Ann Saudi Med.2008;28:169-173

29. Shieh JT, Srivastava D. Heart malformation: what are the chances it could happen again? Circulation.
2009 Jul 28; 120(4): 269-71. doi: 10.1161/ CIRCULATIONAHA. 109.878637. Epub 2009 Jul 13.

30. Bittles AH. A community genetics perspective on consanguineous marriage. Community Genet. 2008; 11 (6):324-30. doi: 10.1159/000133304. Epub 2008 Aug 5.

31. Patel SS, Burns TL. Nongenetic risk factors and congenital heart defects. Pediatr Cardiol. 2013 Oct; 34(7):1535-55. doi: 10.1007/s00246-013-0775-4. Epub 2013 Aug 21.

32. Loffredo CA, WilsonPD, Ferencz C. Maternal diabetes:an independent risk factor for major cardiovascula malformations with increased mortality of affected infants. Teratology. 2001 Aug; 64(2):98-106.

\section{How to cite this article?}

Phuljhele S, Dewangan S, Thombre P. Clinical spectrum of congenital heart diseases in a tertiary care hospital. Int J Med Res Rev 2016;4(12):2114-2119.doi:10.17511 /ijmrr. 2016.i12.06. 